\title{
Do Capitólio ao Foro. Em torno da judicialização da política no Brasil de hoje
}

\section{From the Capitol to the Forum. On the judicialization of politics in today's Brazil}

\author{
RAÚl ENRIQUE ROJO ${ }^{1}$ \\ Doutor em Sociologia pela École des Hautes Études en Sciences Sociales (EHESS) \\ Professor Permanente do Programa de Pós-graduação em Sociologia da UFRGS \\ GABRIEL EIDELWEIN SILVEIRA ${ }^{2}$ \\ Mestre em Sociologia pela Universidade Federal do Rio Grande do Sul (UFRGS) \\ Doutorando em Sociologia (UFRGS)
}

\begin{abstract}
RESUMO: Assistimos hoje no Brasil a uma transformação maior que não é nem política nem jurídica, mas cultural: o espaço próprio da democracia se desloca do capitólio ao foro como resultado de uma nova utilização do direito e da justiça por todos. A começar pelos políticos, que têm descoberto o Tribunal como um novo lugar para fazer política. É assim que a Justiça, que até aqui se tinha limitado a resolver conflitos privados, se transforma em um recurso político a disposição de quem quer que seja. E a mudança não se produz sem mal, porque as instituições judiciais não estavam preparadas para dar conta deste novo uso que delas se faz. A tradicional tolerância brasileira com a falta de efetividade do direito parece estar acabando. Especialmente a respeito das diversas figuras penais relacionadas com a corrupção (ativa e passiva) de funcionários públicos, parlamentares e juízes. Destarte, e ao cabo de processos de grande repercussão, se identifica uma nova demanda dirigida à Justiça, não tanto para reparar danos ou para sancionar uma falta penal, mas para satisfazer uma reivindicação política: ver publicamente reprovado um comportamento ou reconhecida uma dignidade escarnecida.
\end{abstract}

Palavras-chave: Judicialização da política; Democracia adjudicatória; Direito de pleitear.

ABSTRACT: We watch today to a major change in Brazil which is neither politic nor legal, but cultural: the space of democracy itself moves from the Capitol to the Forum as a result of a new use of the Law and the Justice by everyone. Starting by the politicians, who have discovered the Court as a new place to make politics. That's how Justice, until now restricted to solve private controversies, changes itself in a political resource available to anyone, don't matter who. The change is not performed with no wrongs though, because judicial institutions were not ready to deal with this new use that people make of them. The traditional Brazilian tolerance with the lack of legal enforcement seems to be ending. Especially regarding with several criminal rules, related to corruption (either active or passive) of public officers, lawmakers and judges. Hence, after greatly highlighted lawsuits, it is identified a new demand addressed to the Justice, not as much to repair damages or to impose penalties for criminal faults, but to satisfy a political claim: to see publicly disapproved a behavior, or recognized a scorned dignity.

Keywords: Judicialization of politics; Adjudicatory democracy; Right to argue.

\section{INTRODUÇÃO}

Políticos, empresários, funcionários do primeiro escalão do Estado: todo o mundo (ou quase), provenha da situação ou da oposição, se inquieta hoje à raiz do poder (supostamente crescente) da Justiça no Brasil. O papel cada vez maior que a sociedade brasileira reconhece a seus magistrados é, todavia, muito mais o resultado de uma crise das instituições estatais que a causa desta situação crítica. Mas, se a Justiça e o direito respondem a uma demanda política imprecisa da cidadania, é necessário reconhecer também que levam em si mesmos o germe de uma nova política: por isso convém tomar distância de certas queixas interessadas e nos determos nesta nova democracia que se anuncia fragorosamente nos foros de todo o país, para acompanhar dito movimento, mais que para resistir-se a ele de maneira saudosista e, no fundo, estéril.

Em primeiro lugar, pensamos que haveria que se negar a apresentar simplista e erroneamente as relações entre Justiça e democracia (ROJO, 2000). Para tirar deles todo o poder, se diz, assim, que os juízes não têm legitimidade, que se imiscuem em questões que lhes são alheias e que, obrando desta sorte, acabarão por matar as instituições democráticas. Estes argumentos 
dão conta de uma percepção confusa, parcialmente amnésica e bastante paranoica, que demonstra, uma vez mais, que a crise atual é tanto uma crise do Estado como do discurso sobre o Estado que, como não chega a encontrar seus referentes, se precipita no impasse.

\section{UMA DEMOCRACIA ADJUDICATÓRIA}

A revolução à qual assistimos não é nem política, nem jurídica, mas cultural. Consiste em uma nova utilização do direito e da Justiça, em particular da Justiça Criminal. O foro é utilizado por todos, a começar pelos políticos, como um novo espaço para fazer política. É assim que a Justiça, que até ora se tinha limitado a resolver assuntos privados (referentes à família, à propriedade ou aos delitos que ofendiam a um número mais o menos limitado de particulares), se transforma em um recurso político à disposição de todos. O mal-estar provém, precisamente, do fato de que as instituições judiciais não estavam preparadas para dar conta deste novo uso que delas se faz.

A cultura lusa, transplantada aos trópicos, se tem caracterizado por uma distância às vezes bastante grande entre o direito anunciado e o direito aplicado, revelando "uma sociedade com dois ideais: o da igualdade e o da hierarquia", na qual "o sistema legal (importado e aplicado com toda a força) pode ser sistematicamente deformado pela moralidade pessoal" (DAMATTA, 1990, p. 164 e 203). O direito igualitário, aplicado em uma sociedade moldada historicamente sob o signo da honra, "não tem o caráter moderno de impessoalidade e generalidade; a troca de benefícios é a base da atividade pública, dissociada em interesses" (FAORO, 2001, p. 67). Pois bem, ainda que pareça mentira, esta tolerância brasileira com a falta de efetividade do direito (este consenso para aplicá-lo só em certas ocasiões) estaria acabando. Especialmente a respeito de diversas figuras penais relacionadas com a corrupção (ativa e passiva) de funcionários públicos, parlamentares e juízes. Em um país em que Ademar de Barros se fez eleger governador de São Paulo assegurando que ainda que ele roubasse (como todos os outros), em compensação cumpriria com seus compromissos de campanha, são numerosos os que hoje se valem da lei para obter seus objetivos. Uma imprensa à espreita e uma opinião pública especialmente sensível aos temas vinculados à moral pública têm vindo a revirar a antiga regra implícita do jogo. A Justiça Criminal é utilizada para fins civis ou administrativo-fazendários (GARAPON e SALAS, 1996) e um novo Ministério Público, convertido em quarto poder, faz um largo uso de suas faculdades inquisitoriais no processo acusatório, o que não deixa de produzir lamentáveis atritos com os corpos policiais que lhe disputam este papel. Duas lógicas coexistem, então: a lógica do estigma, que caracteriza o direito penal, e a perspectiva reparadora, que deveria denotar a Justiça Criminal.

O Brasil se encontra hoje no cruzamento de dois modos de regulação social: o primeiro, como se tem mencionado, passava mais pela honra que pelas instituições e se mostrou muito mais eficaz que os controles oficiais, mas trouxe como consequência a criação de uma série de falsas instituições de controle, que não cumpriam sua função. $\mathrm{O}$ segundo surge da demanda de setores crescentes da população que exigem destas instituições que exerçam um verdadeiro controle, pedindo aos juízes que desempenhem seu labor. Porém, se a honra não cumpre mais sua função reguladora, as instituições penam a assumir a sua, mesmo porque a boa aprendizagem da atitude republicana pressupunha condições socioculturais diversas das presentes no processo de formação histórica do Estado brasileiro (ROCHA e SILVEIRA, 2009).

Assistimos, assim, atualmente, a uma mudança política maior: o espaço próprio da democracia se desloca do capitólio ao foro (ROJO, 2003). Uma nova representação da política substitui à antiga: se passa do paradigma da administração ao do julgamento. Sem desaparecer, a administração é substituída pela Justiça como espaço no qual a democracia se constrói. E o constructo resultante incorpora (como não poderia ser de outra maneira) certos elementos genéticos, determinadas feições originais que o identificam, a nosso ver, como uma democracia adjudicatória. Onde o modo de ação que chamamos "adjudicatório" se caracteriza pela existência de um terceiro personagem que age à margem dos outros e que, avaliando os argumentos e as provas dos recorrentes em um contraditório, permite finalmente sair de dúvidas mediante uma decisão que declara o que é "justo" fazer.

Uma democracia adjudicatória não é apenas uma democracia regulada pelo direito, mas um regime que projeta seu ideal no processo e no contencioso judicial antes que na administração. É por isso que a democracia de nossos dias privilegia tanto a transparência, o terceiro e o contraditório, procedimentos, todos eles, que tendem a racionalizar a confrontação de interesses divergentes mais que a procurar de maneira direta e crítica o interesse geral. $\mathrm{O}$ procedimento se tem convertido na linguagem de nossas democracias e o aumento do poder da Justiça consagra um novo vocabulário político. Como registrou Garapon, o direito tornouse "a nova linguagem política na qual são formuladas as reivindicações políticas", enquanto "a Justiça se tem convertido em um espaço de exigibilidade da 
democracia", onde "potencialmente todos os cidadãos poderiam interpelar a seus governantes" e "intimá-los a respeitar as promessas contidas na lei" (GARAPON, 1996, p.45).

O processo, tornando-se o novo paradigma da ação política, dá origem a toda uma série de significantes inéditos. Este movimento corresponde, então, tanto a uma simbolização como a uma resimbolização concomitante da política. Mais que o juiz, é o processo quem se encontra no centro deste imaginário. E mais que o processo, é o conflito que se converte no verdadeiro processador da dinâmica social; não já um conflito de classes, coletivo e ideológico, mas um conflito próximo, entre pessoas, entre interesses privados ou corporativos.

E o conflito, como sabemos, tem uma conotação pejorativa no Brasil, como o demonstrou em sua época "Linha Direta" e continua testemunhando-o "Fantástico", "Profissão Repórter" ou outras produções de telejornalismo da Rede Globo, empresa típica de uma sociedade que não sabe regular seus conflitos e que remunera melhor a delação que a denúncia juridicamente argumentada (TEIXEIRA, 2011). Mesmo quando os jornalistas vangloriam-se de possuírem as qualidades de um bom juiz de instrução (paciência, minúcia, tenacidade), a televisão "fala de tudo", exceto da razão pela qual se fala frente às câmaras: divertir, informar, vender (GARAPON, 1996). O próprio jornalismo comercial, mesmo quando age com a melhor das intenções, é vítima de uma "mentalidade de índice-de-audiencia" (BOURDIEU, 1997, p.75).

Todavia, o conflito, como se dizia, é veículo de regulação. A garantia, quando não vem mais "de cima" (de um controle estatal cada vez mais enfraquecido), repousa na capacidade reconhecida aos interesses divergentes de confrontarem-se em um espaço concebido para esse fim. Se o interesse geral não tem mais servidor, ele procede de uma lógica de guerra fria, na qual todos se respeitam por juristas interpostos. O espaço público não é mais um quadro preestabelecido e estável, mas um espaço concebido para agir coletivamente, para avançar com nossos conflitos. Isto é válido para todos, até para os excluídos engendrados por nossas sociedades, para quem o delito se converte em uma oportunidade de socialização.

Quando a transmissão própria de toda iniciação não se faz mais pelas vias naturais da família, da escola ou da nação, se cumpre retroativamente pelo drama do crime (ROJO, 2009). Se ela não pode expressar-se já de forma positiva, se transmitirá negativamente: é a transgressão (e não mais a transmissão) o que permite descobrir a regra. Como bem escreveu Garapon, vemos hoje, em numerosos delitos cometidos por jovens infratores, que o prioritário neles resulta ser o benefício identitário, por cima do eventual proveito econômico (desprezado muitas vezes quando se abandona ou vende a preço vil os bens furtados). "É como se esses adolescentes (provenientes por via de regra de camadas sociais desfavorecidas) só pudessem sair da infância arrombando a porta, privados pela cultura de uma experiência forte de integração" (GARAPON, 1996, p. 122). Como o lembra esse antigo Juiz de Menores francês, a delinquência equivale, assim, para um número cada vez maior de adolescentes, a uma socialização por defeito. A confrontação com a Justiça Criminal consiste na última defesa de sua identidade. Cai-se no escapismo da droga antes de sucumbir no nada de uma existência vazia, se joga de noite ao polícia-e-ladrão com os gendarmes (ou nossos brigadianos) antes de continuar absolutamente ausente do mundo adulto.

Porque o conflito não é unicamente destruidor, mas habilita ao "outro" como "parte": supõe a autonomia e não a infantilização dos adversários. Estar em conflito exige que cada um assuma seus interesses e que não se refugie mais por trás da virtude. E isso obriga à confrontação que o Estado tinha por fim de evitar.

$\mathrm{O}$ processo aparece então como uma (ainda que não a única) das formas de gestão dos conflitos. Como registra Pacheco: "o Poder Judiciário se vê impingido a novas formas de resolução [de conflitos] que, se por um lado obrigam a novas formas de atuação, por outro não podem abandonar todo o espetáculo judicial tradicional, o que se não for mantido pode significar uma profunda fenda na capacidade de controle e domínio do campo jurídico" (PACHECO, 2011, p.144). Pois ao mesmo tempo em que o conflito vai tomando corpo, segrega seu próprio contraveneno, como demonstra o movimento de resolução informal dos conflitos (ROJO, 2004). As ideias de negociação, mediação, compromisso e arbitragem, ainda que sejam formas de evitar o processo, formam parte, apesar de tudo, do mesmo registro de representações. Vêm a substituir a relação assimétrica do Estado e seus cidadãos. Saber administrar as confrontações, organizar-se em atores coletivos de tamanho e peso que permitam fazer-se respeitar, eis a nova linguagem da ação política.

O conflito permite aproveitar a ocasião de formarse a si mesmo, de relatar publicamente uma história (SALMON, 2007). Esta nova democracia inaugura, assim, uma nova relação com a linguagem. O processo é antes de tudo um ato de palavra no qual tudo deve ser formulado, enunciado. Esta é uma de suas contribuições antropológicas objetivas mais importantes e menos visíveis. É neste sentido que Garapon (1996) faz notar que uma das funções da Justiça Criminal é a de ajudar 
a vítima da agressão a fazer seu luto, ressignificando a violência "real" em um quadro "simbólico" no qual as responsabilidades são enunciadas pela linguagem. Pois, se fazemos nosso o léxico psicanalítico-lacaniano, "o real é precisamente aquilo que não pode ser representado nem por palavras nem por imagens" e que, por isso, é insuportável para a pessoa, enquanto "o simbólico corresponde às relações entre inconsciente $\mathrm{e}$ linguagem" (JORGE e FERREIRA, 2005, p. 32).

Podemos ver, desta forma, como em democracias mais jurídicas que as nossas, como as do common law, o processo é um lugar de argumentação, de motivação e elocução da realidade. Em síntese, uma instância de formulação, de construção incessante da democracia. No vindouro, o poder não se enuncia mais diretamente, por si mesmo: tem perdido o controle de sua formulação. Não tem mais donos incontestáveis, se tem tornado incontrolável e tem encontrado nos tribunais um lugar de enunciação. Por acréscimo, a linguagem oficial é tomada sempre ao pé da letra. O escândalo supremo numa democracia é hoje a mentira do homem público, que se converte na negação mesma da palavra empenhada: doravante tudo compromisso deverá ser respeitado.

\section{O DIREITO DE PLEITEAR}

Ser cidadão consiste não apenas em ter direitos, mas também em podê-los fazer valer, quer dizer, em poder pleitear. Neste novo modelo de democracia, a capacidade de fazer-se ouvir pela Justiça se converte em um direito fundamental. Vejamos como começaram os principais escândalos que comoveram os três poderes do Estado brasileiro nos últimos tempos: de Waldomiro Diniz a Xico Lopes, Salvatore Cacciola e à negociata dos Bancos Marka e Fontecindan; do juiz Lalau ou a venta de sentenças no Superior Tribunal de Justiça aos telefones grampeados do BNDES; de Antonio Carlos Magalhães e a violação do painel eletrônico do Senado Federal aos Sete Anões do Orçamento; das contas secretas em paraísos fiscais de Paulo Maluf e sua família às propinas cobradas por fiscais da Receita paulista que tomaram o mesmo caminho; da quadrilha formada, articulada e chefiada por Zé Dirceu e Marcos Valério para comprar o voto de parlamentares por meio de pagos mensais (o mensalão) ao esquema de Roberto Jefferson para preencher os cofres do Partido Trabalhista Brasileiro (PTB). Muitos deles foram o resultado da ação de particulares (jornalistas ou simples informantes) que alertaram ao Ministério Público, quando não se adiantaram a estes como a Ordem dos Advogados do Brasil (OAB), a Conferência Nacional dos Bispos do Brasil (CNBB) ou a Associação Brasileira de Imprensa (ABI) quem se apresentaram perante a Justiça invocando a condição de parte. Estas ações utilizam a Justiça como foro político para satisfazer demandas que as instituições pareciam incapazes de regrar de outra maneira.

Ao cabo de processos de grande repercussão (pensemos nas sessões do Supremo Tribunal Federal durante a tramitação da Ação Penal 470, o caso do mensalão, transmitidas em direto pela televisão meses a fio) se identifica uma nova demanda dirigida à Justiça (ou a um terceiro que faça suas vezes, à condição de agir segundo o modo adjudicatório, como, por exemplo, as comissões parlamentares de inquérito). Estes processos são utilizados não tanto para reparar danos ou para sancionar uma falta penal, mas para satisfazer uma reivindicação política: ver publicamente reprovado um comportamento e reconhecida uma dignidade escarnecida. O objetivo consiste em convocar perante uma instância simbólica um empresário, uma liderança política ou um alto funcionário que parecem não ter de "responsáveis" mais que o nome já que, de fato, nunca tiveram que prestar contas a ninguém por seu descaso a lei (desde a falta de respeito aos sinais de trânsito até a mora no pago de seus impostos). O simples fato de tê-los obrigado a pôr os pés em uma sala de audiências (quando não de vê-los algemados), comprovando que a denuncia foi levada à sério, já é considerado uma vitória.

O recurso cada vez mais frequente ao Tribunal deve assim ser interpretado como a busca de um novo espaço público que, além de suas evidentes carências, tem quando menos a vantagem de oferecer um remédio para diversas frustrações cidadãs. Na palavra responsabilidade encontramos etimologicamente responsus, o particípio passado de respondere, quer dizer a ideia de "responder" e, por consequência, a existência de uma pergunta prévia. A possibilidade de inquirir, de questionar, está na origem de toda responsabilidade. Esta "questionabilidade" (valha o neologismo) é justamente o contrário do acesso à Justiça: não consiste tanto em submeter-se (à lei), mas em obter a submissão da outra parte. O processo se converte, assim, em um espaço de contestação política como o demonstram numerosos litígios que utilizam hoje ao juiz criminal como árbitro de conflitos que aparentemente não podiam ser solucionados em outra sede. Os demandantes de justiça não são necessariamente populistas descridos da política e dos homes públicos, mas cidadãos para quem a Justiça é o último recurso. $\mathrm{O}$ atual movimento de vitimização seria incompreensível se não se advertisse que por trás destes novos demandantes se perfilam novos sujeitos políticos que não fazem mais que exigir seus direitos. 
O processo, colocando o forte e o fraco em pé de igualdade, em um espaço comum, continua encarnando para nossos concidadãos o mito da igualdade democrática, papel que as instituições políticas brasileiras há tempo que deixaram de representar. Advirtamos, por fim, que se estas instituições políticas não podem administrar a desigualdade entre fracos e poderosos têm deixado simplesmente de ser críveis. A "democracia adjudicatória" se converte, assim, em "democracia de opinião” (GARAPON, 1996, p. 73-94).

\section{UMA DEMOCRACIA DE OPINIÃO}

A democracia de opinião exige três ingredientes: a Justiça, os meios de comunicação de massa e a opinião pública. Sua coincidência cria um precipitado explosivo que desata as paixões, inquieta os espíritos, permite que antigos agravos venham à luz, mas também que surjam novas adesões. Em síntese: os extremos! Doravante, a capacidade de mobilização da opinião pública depende especialmente da capacidade de manipular a "agressão ética", da aptidão para suscitar a indignação; daí a importância que hoje cobra a acusação pública. Esta nova democracia de opinião é menos o resultado de uma opção que de uma nova imposição dos novos instrumentos tecnológicos e de um contexto histórico inédito. Suas razões são às vezes perversas, às vezes benéficas, quase sempre desconcertantes. Não há escapatória, então: a política deve transigir com esta nova demanda de moralidade, com suas formas desordenadas e surpreendentes. Uma opinião forjada ao calor de uma imagem não tem as mesmas exigências que outra preferentemente reflexiva. Mais sensível ao visível que aos conceitos e razões, comunicando especialmente através da televisão ou das imagens reproduzidas e transmitidas pelas redes sociais graças ao desenvolvimento exponencial da telefonia celular e seus aparelhos "inteligentes", esta opinião pública é facilmente impressionável, mais reativa ao escândalo, mais disposta ao arrebatamento e também mais esquecidiça. Chega aos extremos com a mesma facilidade com que pode decair seu interesse quando outros escândalos ou crimes violentos deslocam aos precedentes na predileção da mídia. Esta emotividade se acopla a uma política mais espetacular, mais teatral. Doravante, a qualidade mais importante de uma instituição é aquela que seja a mais visível. Isso explica a prioridade concedida à celeridade processual que prefere tratar os delitos "mais simples" (cometidos geralmente pelas pessoas mais simples, também), em detrimento do estudo de outras causas mais complexas (como, por exemplo, as originadas na delinquência econômico-financeira).
Mais sensível às imagens que aos raciocínios complexos, esta nova democracia é necessariamente menos elaborada. A coerência cênica ou a adaptação situacional contam mais que a coesão ideológica, correndo-se o risco de confundirem-se a opinião pública (com sua efemeridade e sua carga emocional) e o contrato social (constituído pelos valores racionais fundantes da sociedade política moderna). Novas demandas e reivindicações antigas são apresentadas, assim, numa farragem que reúne exigências muitas vezes contraditórias com igual convicção e similar autenticidade. A opinião pública se indigna com a pedofilia com o mesmo vigor com que se condói do suicida envergonhado que põe fim a seus dias depois de uma espetacular ação policial que tinha revelado suas condenáveis preferências sexuais. À força de ser adulada pelos políticos em procura de votos, pela publicidade que pretende lhe vender algo, e pela mídia que a toma por um rebanho, a opinião pública acredita que pode exigir tudo e seu contrário. Ao invés da ideologia, que procurando a coerência chegava a ocultar suas inconsequências, a democracia de opinião não teme a contradição. Mais ainda: chega a reivindicá-la! E o discurso político segue seus passos: seus contornos se tornam imprecisos, seus objetivos podem ser contraditórios, seus operadores contradizem impunemente o que anunciaram e, sobretudo, não temem conduzir simultaneamente duas políticas incompatíveis (securitária e liberal, por exemplo).

De fato, se reclama do Estado liberdade e proteção, o que equivale a pedir-lhe que se retire e continue presente. Esta mistura de desejo e rejeição a respeito das instituições é particularmente visível em matéria familiar. O indivíduo parece dizer ao Estado: "protejame se me vou mal, mas deixe-me em paz se me vou bem". Nunca se valorizou tanto a família e, porém, o poder dos pais parece suspeito, susceptível de impor um arbitrário cultural quando não de esconder abusos abomináveis. Como bem ilustra a polêmica jornalística acerca do projeto de Lei 7.672/2010, conhecido como "Lei da Palmada", o rechaço dos limites impostos unido ao culto da desconfiança faz estragos na família. Diferentes casos de pedofilia têm maculado com a sombra da suspeita as profissões em contato com a infância (mestres, sacerdotes, pediatras, assistentes sociais ou escoteiros) que encarnavam antes o desinteresse total e que hoje têm que encarar as dúvidas mais infames.

Esta atitude ambivalente é aplicável à própria Justiça. No Brasil, ao mesmo tempo em que um ministro do Supremo Tribunal Federal (Joaquim Barbosa) se convertia no herói da luta contra a corrupção em sua qualidade de relator da soada causa do mensalão 
(mostrando-se rigoroso a respeito de todos os processados, vinte e cinco dos quais condenou - junto com a maioria do Tribunal - a longas penas de prisão), outro ministro (no caso o revisor da mesma Corte, Ricardo Lewandowski, que defendeu uma atitude muito mais inclinada à absolvição da maioria dos acusados, doze dos quais foram inocentados quando sua postura encontrou apoio suficiente no Tribunal), se converteu no bode expiatório da cólera popular, sendo insultado publicamente quando concorreu a votar nas eleições municipais que se disputaram enquanto tramitava o processo em questão. Evidentemente, se o juiz ocupa uma posição central no novo imaginário democrático se deve a que é simultaneamente o ator principal e o eventual vilão.

Cremos, por isso, que se teria que fazer uma leitura política deste fenômeno que tem por efeito questionar todas nossas referências. Verdadeiramente, não sabemos mais à proteção de que santo nos confiar a ponto tal que tudo poder parece ora suspeito: os depravados se ocultam entre os mestres sem tacha e todo homem político (incluído o aparentemente mais virtuoso) pode acabar sendo um corrupto, como ilustra, por exemplo, a condenação do senador Demóstenes Torres, considerado até apenas ontem um "paladino da moralidade". Mas, a quem aproveita este novo medo ao "crime sem rosto"? Quem se preocupa em desmontar os poderes tradicionais? Não serão os titulares dos novos poderes? Os meios de comunicação de massa, em primeiro lugar, que posam de grandes purificadores da pátria e, com certeza, todos aqueles a quem incomodam as barreiras institucionais e os limites à desregulamentação total. Esta leitura política da importância renovada do direito, não deveria, todavia, conduzir à rejeição sistemática das situações que ela mesma propõe, mas nos invitar a uma análise das necessidades que a mesma tem vindo satisfazer e das reformas nas que pode desembocar.

\section{CONCLUSÕES}

Montesquieu (que se referiu ao "juiz boca da lei" na que é provavelmente a primeira obra de Sociologia Jurídica e talvez de Sociologia tout court dos tempos modernos) não podia imaginar em sua época as consequências possíveis (às vezes muito mais consideráveis que a própria sentença) do comportamento do juiz, de sua atitude e de sua maneira de tratar a causa a ele confiada. Pensemos nas repercussões políticas que pode ter a data escolhida para notificar o processamento a um candidato (antes ou depois das eleições onde pleiteia um cargo, por exemplo), as consequências para a vida de centenas (ou milhares) de trabalhadores que pode ter um ato processual como a aprovação (ou não) de uma concordata ou de uma oferta pública (e inamistosa) de compra de um conglomerado industrial; a sorte enfim do crédito internacional de todo um país, quando se faz lugar ao penhor de bens públicos para garantir um crédito multimilionário (e quiçá duvidoso) contra esse mesmo Estado.

Todavia, nossa cultura cívica (quando existe) se representa a legitimidade como uma pirâmide em cuja cúspide se acham os representantes da nação. A evolução da democracia nos invita, porém, a abandonar esta representação espacial e estereotipada, para compreender que ela é dinâmica, que suas hierarquias rotam e que os titulares do poder são múltiplos e móveis. Não se trata mais de uma pirâmide de normas convergindo para um ponto de fuga último. O eixo deste movimento é agora a norma.

Com efeito, se a confusão de Estado, Governo e Administração Pública impede ao primeiro (quando menos por nossas terras) invocar crivelmente a imparcialidade, esta também não se tem convertido por isso em monopólio da Justiça: a imparcialidade radica em uma regra de jogo que deve ser a mesma para todos, inclusive para o Estado em suas múltiplas dimensões. Esta regra deve reunir três qualidades relativamente novas para nossa cultura jurídica: clareza, realismo e respeito escrupuloso. As melhores intenções do mundo estão fadadas ao fracasso se não se encontram expressas em regras impessoais e comuns. Esta é a regra que hoje padece dos efeitos da corrupção. A primeira virtude da regra de direito é a de ser comutativa: só se pode exigir aos outros que a respeitem se nós nos submetemos a ela. É verdade para a Administração como para os interesses privados e, em geral, para todos os que vivem em sociedade. Pode-se reconhecer aqui o "efeito lealdade" vinculado à regra, seja qual for. A regra não pode pacificar a vida comum a menos de ser impessoal e a mesma para todos.

Se o Estado deve fazer hoje um lugar para um "terceiro poder", tem também que pensar em assegurar sua credibilidade. Não deixa de ser uma novidade para os poderes que se reconhecem a si próprios como "políticos" (Executivo e Legislativo) isto de aceitar um terceiro entre eles e a nação (renunciando assim a dois séculos de "representação exclusiva"), mas também é uma novidade para os juízes. A imparcialidade é tão difícil de aceitar pelos políticos como exigente a realizar pelos magistrados. O desafio lançado às nossas democracias não é então apenas o de repensar a independência da magistratura, mas também sua responsabilidade. É preciso imaginar para o juiz um estatuto que seja ao mesmo tempo protetor e exigente, instância que sugere questões radicalmente 
novas no Brasil como as da representatividade e a responsabilidade do juiz. Como bem lembra Baum (2013), democracias exemplares como os Estados Unidos têm historicamente enfatizado a necessidade de accountability por parte do Poder Judiciário. Pensamos, portanto, que é chegado o momento, devido à própria maturação de nossa democracia, de também a Justiça brasileira reconhecer não só seu "novo poder", mas também suas novas e correlatas responsabilidades.

\section{REFERÊNCIAS}

BAUM, Lawrence. American courts. Process and policy. 7. ed. Boston: Waadsworth, 2013.

BOURDIEU, Pierre. Sobre a televisão. Seguido de A influência do jornalismo e Os jogos olímpicos. Trad. Maria Lúcia Machado. Rio de Janeiro: Jorge Zahar, 1997.

DAMATTA, Roberto. Carnavais, malandros e heróis. Para uma sociologia do dilema brasileiro. 5. ed. Rio de Janeiro: Guanabara, 1990.

FAORO, Raymundo. Os donos do poder. Formação do patronato político brasileiro. 3. ed. São Paulo: Globo, 2001.

GARAPON, Antoine. Le gardien des promesses. Le juge et la démocratie. Paris: Editions Odile Jacob, 1996.

GARAPON, Antoine; SALAS, Denis. La République pénalisée. Paris: Hachette, 1996.
JORGE, Marco Antonio Coutinho; FERREIRA, Nádia Paulo. Lacan, o grande freudiano. Rio de Janeiro: Zahar, 2005.

PACHECO, Antonio Marcelo. Formação humanística. Porto Alegre: Verbo Jurídico, 2011.

ROCHA, Álvaro Filipe Oxley; SILVEIRA, Gabriel Eidelwein. Estado e democracia: esboço de uma interpretação do habitus político brasileiro. Revista de Estudos Constitucionais, Hermenêutica e Teoria do Direito, São Leopoldo, v. 1, n. 1, p. 9-15, 2009.

ROJO, Raúl Enrique. La justicia en democracia. Sociologias, Porto Alegre, v. 2, n. 3, p. 94-126, 2000.

. Jurisdição e civismo: a criação de instâncias para dirimir conflitos no Brasil e no Quebec. In: ROJO, Raúl Enrique. (Org.). Sociedade e direito no Quebec e no Brasil. Porto Alegre: UFRGS, 2003. p. 21-42.

. Justice et citoyenneté: la juridictionnalisation des conflits sociaux au Brésil et au Québec. Revue Juridique Thémis, Montreal, v. 38, n. 1, p. 125-189, 2004.

. Identidade, incerteza e jurisdição. Aula inaugural do curso de Direito das Faculdades Integradas Machado de Assis, Santa Rosa (RS), 2009.

SALMON, Christian. Storytelling. La Machine à fabriquer des histoires et à formater les esprits. Paris: La Découverte, 2007.

TEIXEIRA, Alex Niche. Televisão, hipercrimes e violências na modernidade tardia. In: SANTOS, Tavares dos; TEIXEIRA, José Vicente; NICHE, Alex; RUSSO, Maurício (Orgs.). Violência e cidadania. Práticas sociológicas e compromissos sociais. Porto Alegre: Editora da UFRGS e Sulina, 2011. p. 39-55.

\section{NOTAS}

1 Bacharel em Direito pela Universidade de Buenos Aires (UBA). Mestre em Sociologia pela Pontifícia Universidade Católica Argentina "Santa Maria de los Buenos Aires" (UCA). Doutor em Sociologia pela École des Hautes Etudes en Sciences Sociales (EHESS, Paris). Pós-doutor em Sociologia Jurídica pela Université de Montréal (Canadá), em cujo Centre de Recherche en Droit Public (CRDP) se desempenhou como professor e pesquisador visitante. Ex-docente da Universidade de Buenos Aires. Diretor de pesquisas do Centre de Recherches sur
l'Administration de la Justice et la Société (CRAJS, Paris). Titular da "Chaire des Amériques" da Université de Rennes 2 (Haute Bretagne). Professor permanente dos Programas de Pós-graduação em Sociologia e em Relações Internacionais da Universidade Federal do Rio Grande do Sul (UFRGS). <raulrojo@ufrgs.br>.

2 Bacharel em Direito pela Universidade do Vale do Rio dos Sinos (UNISINOS). Mestre em Sociologia pela Universidade Federal do Rio Grande do Sul (UFRGS). Doutorando em Sociologia (UFRGS), bolsista do Conselho Nacional de Desenvolvimento Científico e Tecnológico (CNPq). Membro do Grupo de Estudos e Pesquisa em Criminologia GEPCRIM (PUCRS). < dr_silveira@yahoo.com>. 